\title{
The Efficacy of Supervised Home-based Pulmonary Rehabilitation in Patients with Chronic Respiratory Disorders
}

\author{
İpek Candemir, Dicle Kaymaz, Pınar Ergün, Neşe Demir, Filiz Cennet Taşdemir, \\ Nurcan Egesel, Fatma Şengül
}

Atatürk Chest Diseases and Chest Surgery Training and Research Hospital, Pulmonary Rehabilitation and Home Care Center, Ankara

\begin{abstract}
Objective: Pulmonary rehabilitation (PR) programs can be carried out in hospital or home basis with a different organizational aspect and program content. This study aimed to evaluate the efficacy of a multidisciplinary supervised home-based PR program in patients with chronic respiratory disorders.

Methods: Forty patients with chronic respiratory disorders who admitted to our center between September 2007 and May 2012 were enrolled. In all patients before and after PR, dyspnea was assessed with Medical Research Council (MRC) dyspnea scale, exercise capacity with Incremental Shuttle Walk Test (ISWT) and Endurance Shuttle Walk Test (ESWT), health related quality of life with St. Geoerge Respiratory Questionnaire (SGRQ), psychosocial evaluation with hospital anxiety and depression scale (HAD), the body composition with bioelectrical impedance method. Ten patients did not complete home-based PR for various reasons.

Results: In patients with Chronic Obstructive Pulmonary Disease (COPD), dyspnea sensation ( $p=0.026)$, exercise capacity ( $p=0.001)$, quality of life $(p=0.001)$, body composition ( $p=0.012)$, anxiety and depression score $(p=0.001)$ improvements were statistically significant. In all patients with COPD and non-COPD perception of dyspnea, exercise capacity, quality of life, anxiety and depression score improvements were above minimal clinically important differences.
\end{abstract}

Conclusion: In this study supervised home-based pulmonary rehabilitation has been shown as an effective and safe modality when applied by an experiencied and multidisciplinary team in selected severe COPD or non-COPD patients.

Keywords: Chronic respiratory disorders, exercise capacity, quality of life, supervised home-based pulmonary rehabilitation

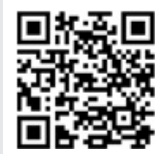

Received Date: 24.01 .2015 Accepted Date: 30.06 .2015 Available Online Date: 09.11 .2015 DOI: 10.5152/ejp.2015.21931

Corresponding Author İpek Candemir

E-mail: ipekcayli@yahoo.com

- Available online at www.eurasianjpulmonol.com

\section{INTRODUCTION}

Chronic pulmonary disease is an important cause of mortality and morbidity, and chronic obstructive pulmonary disease (COPD) is among the most common causes of death. It has been proven that there is an improvement in the quality of life, exercise capacity, and perception of dyspnea in COPD patients with pulmonary rehabilitation (PR), and this is recommended by the guidelines as a non-pharmacological treatment method.

Pulmonary rehabilitation programs are structured at the hospital (as an inpatient or outpatient) and at home (supervised home-based, remotely supervised home-based, or unsupervised home-based). Hospital-centered PR programs with the supervision of outpatients are the most widely accepted applications in stable cases. It was shown in studies that have been conducted that home-based PR (remotely supervised or without supervision) could be an alternative to hospital-centered supervision of outpatients, and there were similar levels of gains in the quality of life and exercise capacity (1). There are a limited number of studies about supervised home-based PR programs. Supervised homebased PR programs can be applied on a hospital-centered basis in ventilator-dependent cases and in patients who have severe disease, are out of condition, or have immobilization or transfer problems in hospitals where there are medical teams to provide home service. 
It was aimed in this study to evaluate the effectiveness of multidisciplinary supervised home-based PR programs in cases that were admitted to our center having chronic respiration problems.

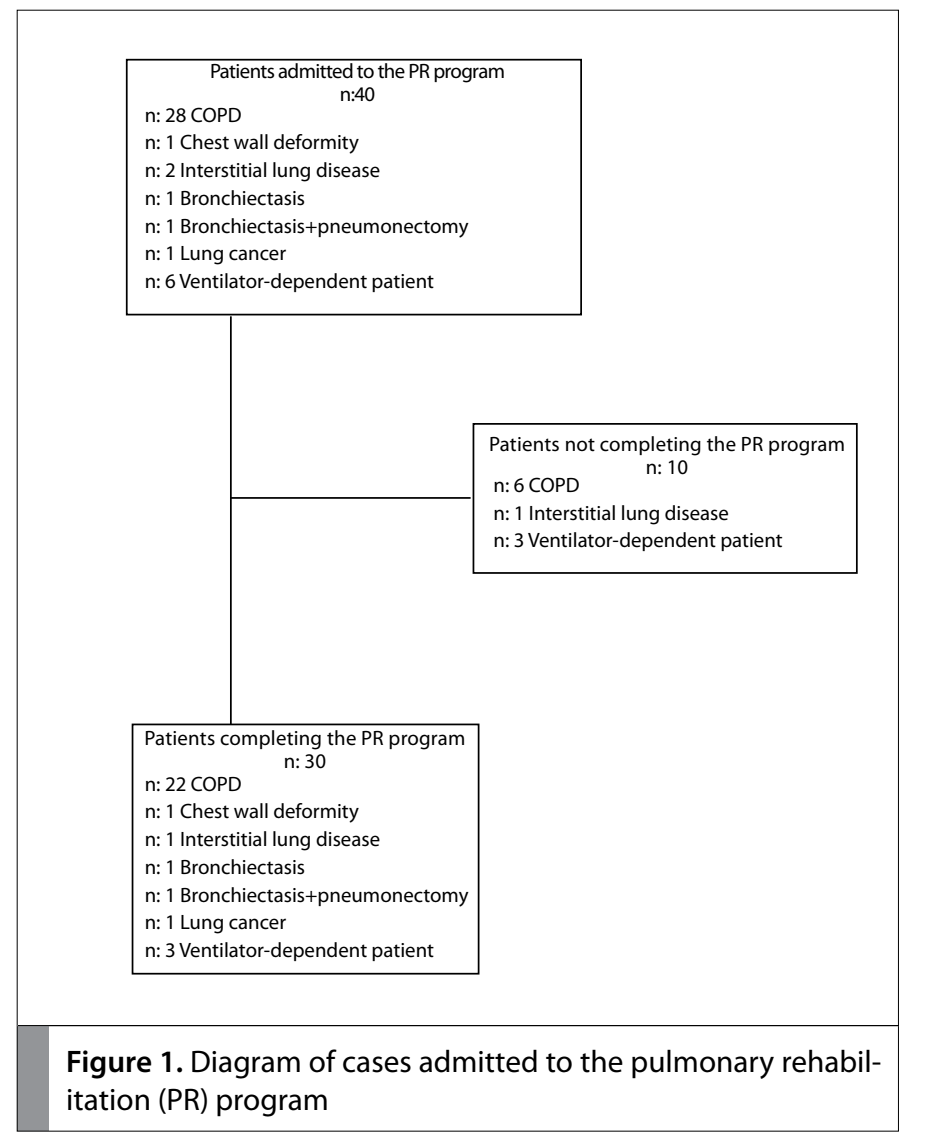

\section{METHODS}

Forty patients having chronic respiration problems who underwent PR with direct observation by our center were evaluated between September 2007 and May 2012. Information on the patients included in the retrospective study was recorded after obtaining the consent of the patients and their relatives. Ten of the patients included in the study could not complete their home PR program because of several reasons (noncompliance, cerebrovascular accident, and acute COPD attack). A diagram of all cases included in the PR program is shown in Figure 1.

Evaluation of the cases before and after PR was performed at our center. The instruments used for evaluation were the Medical Research Council (MRC) dyspnea scale for perception of dyspnea; the incremental shuttle walk test (ISWT) and endurance shuttle walk test (ESWT) for exercise capacity; the St. George's Respiratory Questionnaire (SGRQ) for health-related quality of life; and the Hospital Anxiety and Depression Scale (HAD) for psychosocial evaluation. The severity of dyspnea before and after exercise was determined using the Borg dyspnea scale. Changes of 1 point on the MRC dyspnea scale (2), $47.5 \mathrm{~m}$ in the ISWT, 45-85 s in the ESWT (4), 4 units on the SGRQ, 10 units on the Chronic Respiratory Diseases Questionnaire (CRDQ) (5), and above 10 on both subscores of the HAD scale were regarded as abnormal, and a change of 1.5 units (6) on the HAD scale was regarded as of minimal clinical significance.

The body composition was determined via bioelectrical impedance. The body mass index (BMI) was calculated by dividing the body weight $(\mathrm{kg})$ by the height $(\mathrm{cm})$ squared. The body weight without fat was used to calculate the fat-free mass index (FFMI). A supervised home-based PR program was structured in line with the requirements of the cases.

Table 1. Recorded parameters in patients with COPD

\begin{tabular}{|c|c|c|c|c|c|c|c|}
\hline & \multirow[b]{3}{*}{ n } & \multicolumn{4}{|c|}{ Time of measurement } & \multirow[b]{3}{*}{ z } & \multirow[b]{3}{*}{ p } \\
\hline & & \multicolumn{4}{|c|}{ After PR } & & \\
\hline & & Median (Min; Max) & $\mathrm{M} \pm \mathrm{SD}$ & Median (Min; Max) & $\mathrm{M} \pm \mathrm{SD}$ & & \\
\hline BMI & 22 & $20.2(14.0 ; 34.5)$ & $21.4 \pm 4.9$ & $21.7(16.0 ; 30.5)$ & $22.2 \pm 4.4$ & 2.504 & 0.012 \\
\hline FFM & 22 & $18.2(13.1 ; 21.5)$ & $16.9 \pm 2.1$ & $18.5(15.0 ; 23.8)$ & $17.4 \pm 2.2$ & 1.719 & 0.086 \\
\hline MRC & 22 & $4(2 ; 5)$ & $4.3 \pm 0.7$ & $3(2 ; 5)$ & $3.4 \pm 0.8$ & 3.827 & $<0.001$ \\
\hline Borg (rest) & 17 & $0.5(0.0 ; 3.0)$ & $0.9 \pm 1.1$ & $0.0(0.0 ; 3.0)$ & $0.5 \pm 0.8$ & 2.226 & 0.026 \\
\hline Borg (exercise) & 16 & $3.5(1.0 ; 5.0)$ & $3.4 \pm 1.2$ & $3.0(1.0 ; 7.0)$ & $3.2 \pm 1.4$ & 0.933 & 0.351 \\
\hline ISWT (m) & 22 & $25.0(0.0 ; 280.0)$ & $54.1 \pm 72.6$ & $120.0(11.0 ; 290.0)$ & $137.3 \pm 83.9$ & 4.114 & $<0.001$ \\
\hline ESWT (min) & 22 & $0.0(0.0 ; 13.0)$ & $2.1 \pm 3.6$ & $2.4(0.0 ; 20.0)$ & $5.4 \pm 6.4$ & 4.075 & $<0.001$ \\
\hline SGRQ total & 20 & $77.7(59.8 ; 91.1)$ & $77.0 \pm 8.9$ & $37.7(22.8 ; 78.6)$ & $42.8 \pm 15.0$ & 3.702 & $<0.001$ \\
\hline CRDQ total & 18 & $62.0(45.0 ; 76.0)$ & $60.7 \pm 8.2$ & $98.5(59.0 ; 115.0)$ & $95.3 \pm 15.2$ & 3.681 & $<0.001$ \\
\hline Anxiety & 20 & $9.0(6.0 ; 12.0)$ & $9.3 \pm 2.0$ & $6.0(2.0 ; 14.0)$ & $6.2 \pm 3.0$ & 3.297 & 0.001 \\
\hline Depression & 19 & $10.0(5.0 ; 13.0)$ & $9.8 \pm 2.0$ & $6.0(3.0 ; 13.0)$ & $7.1 \pm 2.7$ & 3.480 & 0.001 \\
\hline $\mathrm{FEV}_{1}, \%$ of expected & 11 & $26.0(17.0 ; 77.0)$ & $35.0 \pm 14.2$ & $30.0(16.0 ; 94.0)$ & $40.6 \pm 27.8$ & 0.490 & 0.624 \\
\hline
\end{tabular}


The PR program involved the following: 1. Exercise training: endurance and strengthening training for the muscles of the lower and upper extremities, respiratory exercises, and training in methods of coping with shortness of breath; 2 . Determination of body composition and supporting treatment; 3. Psychosocial evaluation and supporting treatment; and 4. Training of the patient and patient's relatives.

The exercise training, involving lower and upper-extremity neuromuscular electrical stimulation (NMES) (Uniphy; Myaction Med, Bilzen, Belgium) and active strengthening, bronchial hygiene techniques, methods of coping with shortness of breath, and respiratory exercises, was structured for the person and performed twice a week under the supervision of a physiotherapist and a physician for a minimum of 10 weeks.

\section{Statistical Analysis}

Concordance of the variables to a normal distribution was assessed graphically and with the Shapiro-Wilk test. Median (minimum; maximum) values and mean \pm standard deviation were used to demonstrate the descriptive statistics of the variables. The Wilcoxon signedrank test was employed to compare values before and after PR.

The Statistical Package for the Social Sciences (SPSS) (released in 2012. For Windows, version 21.0. Armonk, NY: IBM Corp.) and MS Excel 2007 programs were used for statistical analyses and calculations. The level of statistical significance was accepted as $p \leq 0.05$.

\section{RESULTS}

The study included 22 patients with COPD, 1 patient with kyphoscoliosis, 1 patient with bronchiectasis, 1 patient with bronchiectasis+left pneumonectomy, 1 patient with lung cancer, 1 patient with

Table 2. Exercise parameters in cases diagnosed with non-COPD pulmonary diseases

\begin{tabular}{|l|c|c|c|c|c|c|}
\multicolumn{4}{|c|}{$\begin{array}{c}\text { Patient diagnosed } \\
\text { with ILD }\end{array}$} & $\begin{array}{c}\text { Patient diagnosed } \\
\text { with lung cancer }\end{array}$ & \multicolumn{2}{c|}{$\begin{array}{c}\text { Patient with } \\
\text { kyphoscoliosis }\end{array}$} \\
\hline & $\begin{array}{c}\text { Before } \\
\text { PR }\end{array}$ & $\begin{array}{c}\text { After } \\
\text { PR }\end{array}$ & $\begin{array}{c}\text { Before } \\
\text { PR }\end{array}$ & $\begin{array}{c}\text { After } \\
\text { PR }\end{array}$ & $\begin{array}{c}\text { Before } \\
\text { PR }\end{array}$ & $\begin{array}{c}\text { After } \\
\text { PR }\end{array}$ \\
\hline BMI & 20.1 & 20.0 & 20 & 24 & 18.3 & 19.6 \\
FFM & 15.1 & 15.7 & 16.3 & 18.2 & 16.6 & 17 \\
MRC & 5 & 4 & 4 & 3 & 5 & 4 \\
Borg (rest) & 1 & 0.5 & 1 & 0 & 0 & 0 \\
\hline Borg (exercise) & 5 & 1 & 2 & 3 & 3 & 0 \\
\hline ISWT (m) & 160 & 160 & 280 & 290 & 130 & 195 \\
\hline ESWT (min) & 2.5 & 4.8 & 3.1 & 5.2 & 1.2 & 2.7 \\
SGRQ total & 94.0 & 36.2 & 82.8 & 69.4 & 80.3 & 35.6 \\
\hline CRDQ total & 48 & 105 & 66 & 59 & 76 & 89 \\
\hline Anxiety & 12 & 9 & 14 & 9 & 10 & 4 \\
\hline Depression & 14 & 10 & 17 & 7 & 10 & 6 \\
\hline
\end{tabular}

BMl: Body mass index; COPD: chronic obstructive pulmonary disease; CRDQ: Chronic Respiratory Diseases Questionnaire; ESWT: endurance shuttle walk test; FFM: fat-free body mass; ILD: interstitial lung disease; ISWT: incremental shuttle walk test; MRC: Medical Research Council; PR: pulmonary rehabilitation; SGRQ: St. George's Respiratory Questionnaire chronic hypersensitivity pneumonia, and 3 cases followed up using a household-type mechanical ventilator who completed the PR program. The mean age of the cases diagnosed with COPD was found to be $68 \pm 9$ years, and the mean parameters that were measured are shown in Table 1. The patients who had a mean $\mathrm{FEV}_{1}$ of $35.0 \pm 14.2 \%$

Table 3. Exercise parameters in cases diagnosed with non-COPD pulmonary diseases

\begin{tabular}{|l|c|c|c|c|}
\hline \multicolumn{3}{|c|}{$\begin{array}{c}\text { Patient with bronchiectasis+ } \\
\text { left pneumonectomy }\end{array}$} & \multicolumn{2}{c|}{$\begin{array}{c}\text { Patient with } \\
\text { bronchiectasis }\end{array}$} \\
\hline BMI & Before PR & After PR & Before PR & After PR \\
FFM & 27.8 & 29.1 & 28.1 & 29.2 \\
MRC & 16 & 17 & 17.3 & 17.6 \\
Borg (rest) & 5 & 4 & 5 & 4 \\
Borg (exercise) & 7 & 2 & 2 & 1 \\
ISWT (m) & Immobile & 70 & 60 & 120 \\
\hline ESWT (min) & 0 & 9.5 & 1.2 & 2.4 \\
SGRQ total & 96.0 & 40.8 & 72.1 & 30.6 \\
\hline CRDQ total & 58 & 101 & 47 & 71 \\
Anxiety & 12 & 7 & 9 & 8 \\
\hline Depression & 11 & 7 & 8 & 6 \\
\hline
\end{tabular}

BMI: Body mass index; COPD: chronic obstructive pulmonary disease; CRDQ: Chronic Respiratory Diseases Questionnaire; ESWT: endurance shuttle walk test; FFM: fat-free body mass; ISWT: incremental shuttle walk test; MRC: Medical Research Council; PR: pulmonary rehabilitation; SGRQ: St. George's Respiratory Questionnaire

Table 4. Exercise parameters in patients followed up using invasive household-type ventilator

\begin{tabular}{|l|c|c|c|c|c|c|}
\hline \multicolumn{4}{|c|}{ Case 1 } & \multicolumn{2}{c|}{ Case 2 } & \multicolumn{2}{c|}{ Case 3 } \\
\hline & $\begin{array}{c}\text { Before } \\
\text { PR }\end{array}$ & $\begin{array}{c}\text { After } \\
\text { PR }\end{array}$ & $\begin{array}{c}\text { Before } \\
\text { PR }\end{array}$ & $\begin{array}{c}\text { After } \\
\text { PR }\end{array}$ & $\begin{array}{c}\text { Before } \\
\text { PR }\end{array}$ & $\begin{array}{c}\text { After } \\
\text { PR }\end{array}$ \\
\hline BMI & 28.5 & 29.9 & 16.6 & 16.6 & 19.4 & 20.8 \\
FFM & 16.6 & 17.6 & 15.3 & 15.3 & 14.1 & 15 \\
MRC & 5 & 3 & 5 & 4 & 4 & 3 \\
Borg (rest) & 5 & 3 & 7 & 3 & 5 & 3 \\
Borg (exercise) & 10 & 4 & 10 & 5 & 7 & 3 \\
\hline ISWT (m) & Immobile & 80 & Immobile & 40 & Immobile & 220 \\
\hline SGRQ total & 94.9 & 41.6 & 82.6 & 45.5 & 77.7 & 35.3 \\
\hline CRDQ total & 56 & 98 & 47 & 74 & 64 & 76 \\
\hline Anxiety & 10 & 8 & 10 & 8 & 10 & 5 \\
\hline Depression & 9 & 6 & 9 & 7 & 7 & 4 \\
\hline
\end{tabular}

BMI: Body mass index; CRDQ: Chronic Respiratory Diseases Questionnaire; ESWT: endurance shuttle walk test; FFM: fat-free body mass; ISWT: incremental shuttle walk test; MRC: Medical Research Council; PR: pulmonary rehabilitation; SGRQ: St. George's Respiratory Questionnaire 
of the expected value were Stage 3-4 according to Global Initiative for Chronic Obstructive Lung Disease (GOLD) post-bronchodilator spirometric evaluation. Eleven cases were Group D and four cases were Group B according to the combined evaluation. Seven cases who had a performance status of Eastern Cooperative Oncology Group (ECOG) 4 could not take part in spirometric evaluation, and $\mathrm{FEV}_{1}$ values were not recorded. Exercise tests could not be applied in these cases and ISWT distances were recorded as 0 . The mean ISWT distance in COPD cases was calculated to be $54.1 \pm 72.6 \mathrm{~m}$. Statistically significant changes were observed in MRC $(p=0.001)$, Borg resting scale $(p=0.026)$, ISWT $(p=0.001)$, ESWT $(p=0.001), B M I(p=0.012)$, SGRQ total $(p=0.001)$, CRDQ total $(p=0.001)$, and HAD $(p=0.001)$ scores after PR (Table 1).

An increase that was greater than the clinically significant change was observed in the MRC, Borg scale after exercise, ESWT, SGRQ, $C R D Q$, and HAD scores of the case diagnosed with chronic hypersensitivity pneumonia and in the MRC, Borg scale, ISWT, ESWT, SGRQ, $C R D Q$, and depression scores of the case diagnosed with bronchiectasis. For the three patients with improved body composition and with diagnoses of bronchiectasis+left pneumonectomy, kyphoscoliosis, and lung cancer, all gains were found to be above the minimum clinically significant values (Tables 2,3 ).

An improvement that was more than the clinically significant level was seen after supervised home-based PR in the MRC, Borg scale, SGRQ, CRDQ, and HAD scores, and ISWT distance of the cases with COPD (Cases 1, 3) and the case with kyphoscoliosis (Case 2), among the cases followed up using a household-type mechanical ventilator (Table 4).

\section{DISCUSSION}

Currently, PR has an important place in the management of cases with chronic respiration problems. The attainment of individual independence, social participation, and skills at the highest level and their continuation are the targets of PR programs (7). Despite its many proven effects, it was reported in the literature that the rate of participation in PR fell to $50 \%$ and the discontinuation rate was $23-31 \%$ (8-10). In the studies conducted, transportation, work conditions, a level of increased shortness of breath, and low social support were observed to be among the reasons for noncompliance and nonattendance in PR programs $(8,9,11-13)$. Those who have transportation and work problems or a high level of perception of shortness of breath as well as advanced-stage and bedbound cases also benefit from PR by means of supervised home-based, remotely supervised, and unsupervised programs. In this study, it was demonstrated that supervised home-based PR is a method that is structured by experienced teams and could be applied not only in COPD cases but also in all cases with chronic problems, even at advanced stages.

Most of the studies were conducted with cases diagnosed with COPD, and a few studies were structured as supervised home-based PR programs. In a meta-analysis published in 2014, 18 studies that involved cases with a diagnosis of COPD to whom supervised home-based/ unsupervised PR programs were applied and cases with a diagnosis of COPD who did not receive PR were examined. Although there were gains in the perception of dyspnea [Borg, basal dyspnea index (BDI)], quality of life (CRDQ, SGRQ), exercise capacity (6 min walk test), and respiratory functions $\left(F E V_{1} / F V C\right)$ in the group receiving $P R$, there was no significant difference between the two groups in admission to hospital, mortality, or maximum workload (14).

In a review comprising 12 studies that included cases who were stable clinically and over 60 years of age with GOLD spirometric Stage 3-4 COPD, both statistically and clinically significant improvements in the quality of life and a statistically significant improvement in exercise capacity were observed. Moreover, when outpatient hospital-based and remotely supervised home-based/unsupervised structured PR programs were compared, it was seen that the gains in the quality of life and exercise capacity were similar, and the differences between them were not statistically significant (1). When the perception of PR was examined, although a decrease was observed in both groups in one of the studies that were compared (15), a decrease was found only in the group receiving PR in the other study (16). The Borg scale after exercise was used in five studies $(15,17-20)$, and a decrease was observed in the Borg scale in remotely supervised home-based PR in four studies (17-20). In this study, there were gains in the perception of dyspnea, exercise capacity, and quality of life in all cases, with and without a diagnosis of COPD, after a supervised home-based PR program.

In a study conducted on patients with a diagnosis of interstitial lung disease (21) and in two studies performed on patients diagnosed with idiopathic pulmonary fibrosis $(22,23)$, a decline was observed in exercise capacity and perception of dyspnea with remotely supervised home-based PR; however, no change was seen in respiratory functions. In a study in which 286 cases with chronic respiration problems were included, remotely supervised home-based PR and outpatient hospital-based PR programs were compared; similar gains were observed in the quality of life and exercise capacity in both groups. In the same study, although a significant improvement was not observed in the HAD score of the outpatient hospital-based group, a significant improvement was observed in the group that received remotely supervised home-based PR (24). In this study, a clinically significant improvement was observed in the two subscores of the HAD scale in all patients undergoing PR. This improvement in the HAD scores was statistically significant in COPD patients. Furthermore, gains were observed in body composition, quality of life, perception of dyspnea, and exercise capacity in the cases, except for COPD.

One of the limitations of this study is the insufficient number of nonCOPD patients and that the distribution of diagnoses is heterogeneous. However, it was found to be a valuable reflection of the first experiences in Turkey of the application of hospital-centered supervised home-based multidisciplinary PR.

\section{CONCLUSION}

Supervised home-based PR is an effective, safe method that results in gains in the quality of life, perception of dyspnea, exercise capacity, and psychological state in ventilator-dependent cases and patients with COPD or non-COPD chronic respiratory disorders who have serious disease, are out of condition, or have immobilization or transfer problems. This procedure is performed in hospitals that have experienced medical home teams with adequate equipment.

Ethics Committee Approval: Ethics committee approval was not received because the study was observational, not experimental.

Informed Consent: Written informed consent was obtained from patients and the parents of the patients who participated in this study. 
Peer-review: Externally peer-reviewed.

Author Contributions: Concept - I.C., P.E.; Design - P.E., D.K.; Supervision - D.K., I.C.; Materials - D.K., P.E.; Data Collection and/or Processing - D.K., N.D., I.C., F.C.T., N.E., F.S.; Analysis and/or Interpretation - I.C., P.E.; Literature Review - I.C.; Writer - I.C., D.K.; Critical Review - P.E., I.C.

Conflict of Interest: No conflict of interest was declared by the authors.

Financial Disclosure: The authors declared that this study has received no financial support.

\section{REFERENCES}

1. Vieira DS, Maltais F, Bourbeau J. Home-based pulmonary rehabilitation in chronic obstructive pulmonary disease patients. Curr Opin Pulm Med 2010; 16: 134-43. [CrossRef]

2. De Torres JP, Pinto-Plata V, Ingenito E, Bagley P, Gray A, Berger R, et al. Power of outcome measurements to detect clinically significant changes in pulmonary rehabilitation of patients with COPD. Chest 2002; 121: 1092-8. [CrossRef]

3. Ries AL. Minimally clinically important difference for the UCSD Shortness of Breath Questionnaire, Borg Scale, and Visual Analog Scale. COPD 2005; 2: 105-10. [CrossRef]

4. Jones PW, Beeh KM, Chapman KR, Decramer M, Mahler DA, Wedzicha JA. Minimal clinically important differences in pharmacological trials. Am J Respir Crit Care Med 2014; 189: 250-5. [CrossRef]

5. Jones PW. St. George's Respiratory Questionnaire: MCID. COPD 2005; 2: 75-9. [CrossRef]

6. Bhandari NJ, Jain T, Marolda C, ZuWallack RL. Comprehensive Pulmonary Rehabilitation Results in Clinically Meaningful Improvements in Anxiety and Depression in Patients With Chronic Obstructive Pulmonary Disease. J Cardiopulm Rehabil Prev 2013; 33: 123-7. [CrossRef]

7. Puhan MA, Gimeno-Santos E, Scharplatz M, Troosters T, Walters EH, Steurer J. Pulmonary rehabilitation following exacerbations of chronic obstructive pulmonary disease. Cochrane Database Syst Rev 2011; 10: CD005305. [CrossRef]

8. Keating A, Lee A, Holland AE. What prevents people with chronic obstructive pulmonary disease from attending pulmonary rehabilitation? A systematic review. Chron Respir Dis 2011; 8: 89-99.

9. Fischer MJ, Scharloo M, Abbink JJ, van't Hul AJ, van Ranst D, Rudolphus $A$, et al. Drop-out and attendance in pulmonary rehabilitation: the role of clinical and psychosocial variables. Respir Med 2009; 103: 1564-71. [CrossRef]

10. Garrod R, Marshall J, Barley E, Jones PW. Predictors of success and failure in pulmonary rehabilitation. Eur Respir J 2006; 27: 788-94. [CrossRef]

11. Fischer MJ, Scharloo M, Abbink JJ, Thijs-Van A, Rudolphus A, Snoei L, et al. Participation and drop-out in pulmonary rehabilitation: a qualitative analysis of the patient's perspective. Clin Rehabil 2007; 21:212-21. [CrossRef]
12. Sabit R, Griffiths TL, Watkins AJ, Evans W, Bolton CE, Shale DJ, et al. Predictors of poor attendance at an outpatient pulmonary rehabilitation programme. Respir Med 2008; 102: 819-24. [CrossRef]

13. Young $P$, Dewse $M$, Fergusson $W$, Kolbe J. Respiratory rehabilitation in chronic obstructive pulmonary disease: predictors of nonadherence. Eur Respir J 1999; 13: 855-9. [CrossRef]

14. Liu XL, Tan JY, Wang T, Zhang Q, Zhang M, Yao LQ, et al. Effectiveness of home-based pulmonary rehabilitation for patients with chronic obstructive pulmonary disease: a meta-analysis of randomized controlled trials. Rehabil Nurs 2014; 39: 36-59. [CrossRef]

15. Murphy N, Bell C, Costello RW. Extending a home from hospital care programme for COPD exacerbations to include pulmonary rehabilitation. Respir Med 2005; 99: 1297-302. [CrossRef]

16. Regiane Resqueti V, Gorostiza A, Gáldiz JB, López de Santa María E, Casan Clará P, Güell Rous R. Benefits of a home-based pulmonary rehabilitation program in patients with chronic obstructive pulmonary disease. Arch Bronconeumol 2007; 43: 599-604. [CrossRef]

17. Fernández AM, Pascual J, Ferrando C, Arnal A, Vergara I, Sevila V. Home-based pulmonary rehabilitation in very severe COPD: is it safe and useful? J Cardiopulm Rehabil Prev 2009; 29: 325-31. [CrossRef]

18. Strijbos JH, Postma DS, van Altena R, Gimeno F, Koëter GH. A comparison between an outpatient hospital-based pulmonary rehabilitation program and a home-care pulmonary rehabilitation program in patients with COPD. A follow-up of 18 months. Chest 1996; 109: 366-72. [CrossRef]

19. Boxall AM, Barclay L, Sayers A, Caplan GA. Managing chronic obstructive pulmonary disease in the community. A randomized controlled trial of homebased pulmonary rehabilitation for elderly housebound patients. J Cardiopulm Rehabil 2005; 25: 378-85. [CrossRef]

20. Hernández MT, Rubio TM, Ruiz FO, Riera HS, Gil RS, Gómez JC. Results of a home-based training program for patients with COPD. Chest 2000; 118: 106-14. [CrossRef]

21. Jastrzebski D, Gumola A, Gawlik R, Kozielski J. Dyspnea and quality of life in patients with pulmonary fibrosis after six weeks of respiratory rehabilitation. J Physiol Pharmacol 2006; 57: 139-48.

22. Holland $A E$, Hill CJ, Conron M, Munro P, McDonald CF. Short term improvement in exercise capacity and symptoms following exercise training in interstitial lung disease. Thorax 2008; 63: 549-54. [CrossRef]

23. Ozalevli S, Karaali HK, Ilgin D, Ucan E. Effect of home-based pulmonary rehabilitation in patients with idiopathic pulmonary fibrosis. Multidiscip Respir Med 2010; 5: 31-7. [CrossRef]

24. Grosbois JM, Le Rouzic O, Monge E, Bart F, Wallaert B. Comparison of home-based and outpatient, hospital-based, pulmonary rehabilitation in patients with chronic respiratory diseases. Rev Pneumol Clin 2013; 69: 10-7. [CrossRef] 